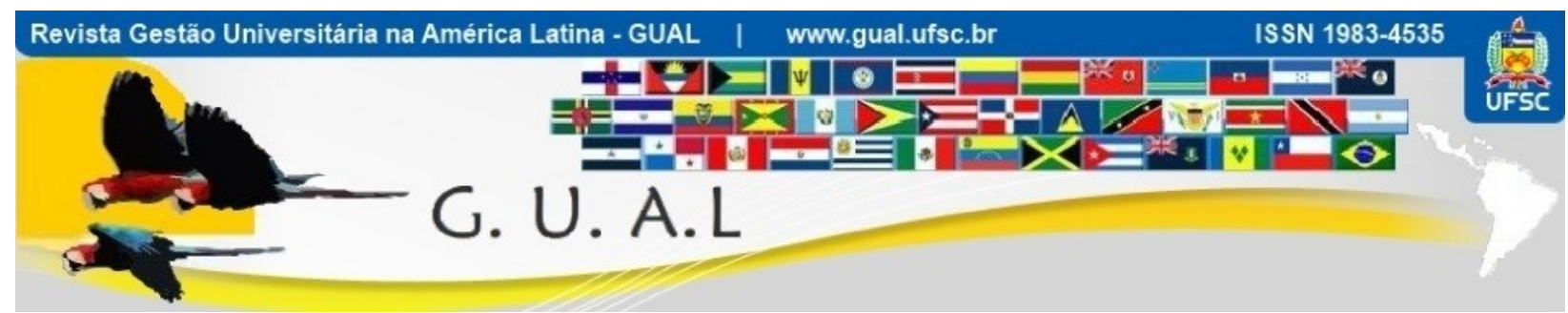

DOI: http://dx.doi.org/10.5007/1983-4535.2018v11n1p298

\title{
A INSTITUCIONALIZAÇÃO DO TEMA SUSTENTABILIDADE NO CURSO DE GRADUAÇÃO EM ADMINISTRAÇÃO
}

THE INSTITUTIONALIZATION OF SUSTAINABILITY TOPIC IN THE BUSINESS ADMINISTRATION COURSE

Indiara Beltrame, Mestre Universidade Norte do Paraná - UNOPAR profaindiarabeltrame@ hotmail.com

Luciano Gomes dos Reis, Pós-doutor Universidade Estadual de Londrina - UEL lucianoreis@uel.br

Karina Rocha Henriques Gehlen, Mestre Universidade Positivo karina.gehlen@up.edu.br

Recebido em 30/maio/2016

Aprovado em 15/setembro/2017

Sistema de Avaliação: Double Blind Review

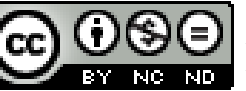

Esta obra está sob uma Licença Creative Commons Atribuição-Uso. 


\title{
A INSTITUCIONALIZAÇÃO DO TEMA SUSTENTABILIDADE NO CURSO DE GRADUAÇÃO EM ADMINISTRAÇÃO \\ DOI: http://dx.doi.org/10.5007/1983-4535.2018v11n1p298
}

\section{RESUMO}

Esse trabalho tem como objetivo geral analisar como se deu o processo de institucionalização do tema sustentabilidade no curso de graduação de Administração da Universidade Estadual de Londrina. Para atingir esse intento foi utilizado como base analítica a teoria de Tolbert e Zucker (1999) que subdivide o processo de institucionalização em três fases: habitualização, objetificação e sedimentação. Quanto à metodologia essa pesquisa caracteriza-se como qualitativa, com fins descritivos e estudo de caso. Mediante análise dos documentos legais e institucionais que contemplam a construção do curso de administração, foi possível identificar pontos de convergência para a inserção da sustentabilidade, verificando-se que o curso atende as normativas legais do ensino de administração e que a sua Proposta Pedagógica (PPC) temse a temática sustentabilidade. No que é pertinente ao exame do processo de institucionalização, se observou as seguintes perspectivas: a temática sustentabilidade está pré-institucionalizada no curso de administração; a opção pela temática sustentabilidade no curso de administração da UEL foi assinalada como oriunda de exigências sociais, de forma natural e espontânea, motivada pela busca de uma formação mais ampla para o administrador, e que se encontra materializada na proposta da uma matriz curricular que contempla o tema de forma transversal.

Palavras-chave: Processo de Institucionalização. Sustentabilidade. Graduação em Administração.

\begin{abstract}
The objective of this work is to analyze how the Londrina State University Business Administration Undergraduate Course carried out the process of the institutionalization topic of sustainability. To meet this goal the analysis was based on the theory of Tolbert and Zucker (1999) which subdivides the institutionalization process into three phases: habitualization, objectivation and sedimentation. As for the methodology, this research is characterized as qualitative, with descriptive objectives, and case study. Analysis of the legal and institutional documents related to the creation of a Business Administration course in order to identify convergence points to include the sustainability theme showed that the course complies with the all legal norms and that the sustainability theme is already included in its pedagogical proposal (PPC). In what is relevant to the examination of the institutionalization process,pointed out to the following perspectives: the sustainability process is pre-institutionalized in the Business Administration courses; the option for the institutionalization theme at the Londrina State University Business Administration course was mentioned as being the result of natural and spontaneous social demands motivated by the search for a wider business administrator's educational process, materialized in the proposal for a curriculum that contemplates the sustainability as a transversal theme.
\end{abstract}

Keywords: Institutionalization Process. Sustainability. Business Administration Undergraduate Course. 


\section{A INSTITUCIONALIZAÇÃO DO TEMA SUSTENTABILIDADE NO CURSO DE GRADUAÇÃO EM

\section{INTRODUÇÃO}

As discussões sobre Sustentabilidade têm ocupado cada vez mais lugar nos distintos ambientes. Governos, empresas, instituições nacionais e internacionais, Organizações não Governamentais (ONGs) têm se interessado em entender o cenário ambiental, econômico e social que se configura nos dias de hoje. Nesse sentido, VanMarrewijk (2003) destaca que tem ocorrido um intenso debate entre os acadêmicos, consultores e executivos de empresas, resultando em muitas definições sobre uma forma mais humana, mais ética e mais transparente de fazer negócios.

Dentre esses debates contemporâneos, dar-se-á especial atenção à institucionalização da sustentabilidade no ensino de administração, uma vez que as Instituições de ensino superior brasileiras estão sendo impulsionadas a atender a demandas sociais e contêmporaneas. Gonçalves-Dias et al. (2009) aponta que os avanços da consciência ambiental ainda representam um desafio para as escolas de gestão, exigindo um repensar dos métodos de ensino em Administração.

Trata-se neste caso de mudanças significativas, pois implicam na incorporação de temas emergentes, eleitos como relevantes pela sociedade, na grade curricular das Instituições de Ensino. Por considerar a importância do papel das organizações educacionais na formação de profissionais, e a relevância da inclusão de temas atuais e importantes nos Currículos Escolares, esse estudo busca responder à seguinte questão: como se deu o processo de institucionalização do tema sustentabilidade no curso de graduação em Administração da Universidade Estadual de Londrina?

Neste contexto de busca pela institucionalização da sustentabilidade nos cursos de graduação em Administração, Carvalho, Vieira e Silva (2012, p. 475) advogam que é consenso nas discussões relativas às novas tendências teóricas e de investigação sociológicas. No que se refere às implicações práticas, considera-se esse estudo relevante, uma vez que os cursos de Administração possuem, de acordo com as diretrizes curriculares do Ministério da Educação (BRASIL, 2005), a função de desenvolver nos acadêmicos a capacidade de transferir conhecimentos da vida e das experiências cotidianas para o ambiente de trabalho, assim como no seu campo de atuação profissional. Nessa perspectiva, esse trabalho busca entender como se tem dado a institucionalização nos processos educacionais do tema sustentabilidade, por este ter reflexos diretos na formação dos futuros administradores, com 
impacto em suas vidas profissional e consequentemente na sociedade onde esses profissionais atuam.

\section{TEORIA INSTITUCIONAL}

Machado-da-Silva et al. (2003, p. 179) afirmam que a "inserção da perspectiva institucional de análise no campo dos estudos organizacionais é crescente, em termos quantitativos e qualitativos". Para os autores, considerando os trabalhos seminais dos "pioneiros, nas décadas de 40 e 50, até os mais contemporâneos como Meyer e Rowan (1977), DiMaggio e Powell (1983) e Scott, (1995) verifica-se significativa evolução de base sociológica na Teoria Institucional".A origem desta teoria de acordo com Vieira $(2005$, p. 9) “ocorreu a partir do trabalho de Robert Merton e seus discípulos no final da década de 1940". Tolbert e Zucker (1999), por sua via, destacam que, no campo da sociologia, os estudos organizacionais têm uma história que pode ser considerada relativamente curta, uma vez que as organizações não eram consideradas como fenômeno social pelos sociólogos até o fim da década de 40.

Pode-se dizer que uma das maiores marcas produzidas pelo trabalho de Merton e seus discípulos foi à dinâmica da mudança social.No que se refere ao estudo das organizações, a perspectiva institucional segundo Rossetto e Rossetto (2005, p. 5):

\footnotetext{
Pode ser tipificada como uma abordagem simbólico-interpretativa da realidade organizacional, apresentando uma posição epistemológica predominantemente subjetivista, na qual é salientada a construção social da realidade organizacional.
}

Nesse sentido a Teoria Institucional trata de interpretação sobre realidade e sobrevivência da organização (Carvalho, Vieira e Lopes, 1999), busca pela superação de dicotomias (Crubellate, 2007) e, indica que a sobrevivência das organizações depende da capacidade de atendimento às orientações coletivamente compartilhadas (Machado-da-Silva e Fonseca, 2010).Em seu trabalho Selznick (1996, p. 271) postulou uma distinção entre 'organização' e 'instituição' afirmando que “uma organização institucionalizada tende a assumir uma característica especial para alcançar uma competência distintiva."

DiMaggio e Powell (1983) argumentam que o isomorfismo institucional é a razão preponderante pela qual as organizações assumem determinadas formas. Apontam que as organizações tendem a apresentar uma homogeneidade de formas e práticas organizacionais, a qual pode ser explicada através do conceito do isomorfismo, que são divididos em três tipos: Isomorfismo Mimético: Ocorre quando a incerteza permeia o ambiente ou quando os 


\section{A INSTITUCIONALIZAÇÃO DO TEMA SUSTENTABILIDADE NO CURSO DE GRADUAÇÃO EM ADMINISTRAÇÃO \\ DOI: http://dx.doi.org/10.5007/1983-4535.2018v11n1p298}

objetivos organizacionais não estão bem claros. Neste caso, a organização tende a se modelar em outra para se manter legitimada; Isomorfismo Normativo: Acontece quando se tem uma demarcação de condições, métodos e práticas comuns ao exercício de uma ocupação, definidas por meio de um compartilhamento de normas e conhecimentos com outros indivíduos, gerando uma similaridade entre diferentes organizações. O último tipo é o Isomorfismo Coercitivo: Ocorre por meio de ações impostas pelo Estado ou por crenças simplesmente impostas pelo esquema interpretativo operante no ambiente. Resulta de pressões formais e/ou informais exercidas por uma organização sobre outra em condição de dependência.Em uma instituição, conforme Tolbert e Zucker (1999), o resultado ou o estágio final de um processo de institucionalização é definido como uma tipificação de ações tornadas habituais por tipos específicos de atores. Os mesmos autores propõem um modelo dividido em três fases: habitualização, objetificação e sedimentação (Figura 1).

Figura 1 Processo de Institucionalização

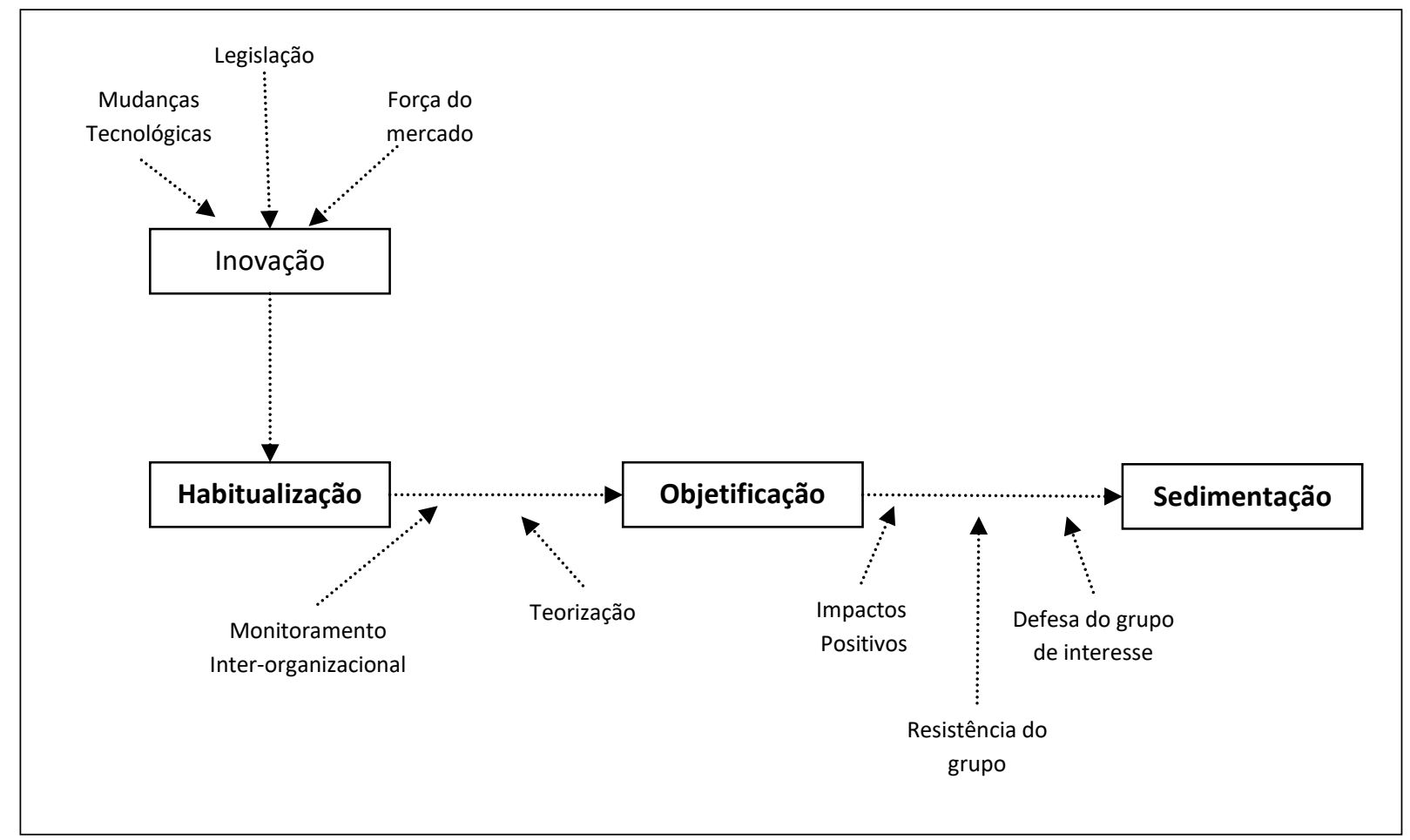

Fonte: Tolbert e Zucker (1999, p. 205).

A habitualização, sendo a primeira fase do processo ocorre como uma resposta a problemas ou mesmo a um conjunto de problemas organizacionais específicosAlves (2012).É nesta fase que acontece a normalização das novas estruturas em políticas e procedimentos de 


\section{A INSTITUCIONALIZAÇÃO DO TEMA SUSTENTABILIDADE NO CURSO DE GRADUAÇÃO EM \\ DOI: http://dx.doi.org/10.5007/1983-4535.2018v11n1p298}

uma dada organização, ou um conjunto de organizações, que encontrem problemas iguais ou semelhantes (TOLBERT; ZUCKER, 1999). A segunda fase do processo de Institucionalização é onde está o movimento em direção a um status mais permanente e disseminado. A objetificação envolve o desenvolvimento de certo grau de consenso social entre os tomadores de decisão da organização a respeito do valor da estrutura e a crescente adoção pelas organizações com base nesse consenso (TOLBERT; ZUCKER, 1999). Na terceira e última fase do processo, "a institucionalização total envolve sedimentação, um processo que fundamentalmente se apoia na continuidade da estrutura e, especialmente, na sua sobrevivência através de gerações de membros da organização." (TOLBERT; ZUCKER, 1999, p. 207).

Assim, conforme os autores, a institucionalização total da estrutura depende do efeito, de um lado, da baixa resistência relativa por parte de grupos de oposição; e, de outro, da promoção de um apoio cultural contínuo por grupos defensores. Vieira (2005) disserta que a institucionalização pode ser dividida em três estágios: pré-institucionalizada, semiinstitucionalizada e institucionalizada. Durante o estágio da pré-intitucionalização, a característica que predomina entre os adotantes é homogeneização, sendo que o ímpeto para a difusão é a imitação; a atividade de teorização é nula, a variância na implementação é alta, bem como é alta a taxa de fracasso da estrutura. Já no segundo estágio, semiinstitucionalização, os adotantes explicitam características heterogêneas, o ímpeto para a difusão passa a ser normativo/imitativo; teorização é alta neste estágio, com variância na implementação, e a taxa de fracasso estrutural moderados. No estágio de institucionalização total, os adotantes também possuem características heterogêneas, o ímpeto para difusão passa a ser normativa; teorização, a variância na implementação e a taxa de fracasso estrutural são baixas (VIEIRA, 2005).

Nesse sentido o resultado de uma instância de institucionalização é uma prática institucionalizada, como regra, inovação tecnológica(LAWRENCE; WINN; JENNINGS, 2001). Nesse nível, é possível verificar o estágio de legitimação da instituição com difusão das práticas dentre os membros participantes. Por fim, tem-se a fase da "desinstitucionalização" que é caracterizada pelo surgimento e implantação de novas inovações (ALVES, 2012). Freitas e Guimarães (2005) explicam que a desinstitucionalização (que constitui a reversão de todo o processo) que ocorre diante de uma grande mudança do ambiente. 


\section{A INSTITUCIONALIZAÇÃO DO TEMA SUSTENTABILIDADE NO CURSO DE GRADUAÇÃO EM

\subsection{DESENVOLVIMENTO SUSTENTÁVEL, SUSTENTABILIDADE E}

SUSTENTABILIDADE ORGANIZACIONAL

No que se refere ao Desenvolvimento Sustentável (DS), foi a partir do relatório da Comissão Mundial sobre Meio Ambiente e Desenvolvimento (World Comission on Environmental and Development - WCED), conhecido como Relatório Brundtland (WORLD COMMISSION ON ENVIRONMENT AND DEVELOPMENT, 1987), que se propôs a possibilidade do alcance da sustentabilidade sem que houvesse mudanças significativas no sistema econômico (CARVALHO; ALMEIDA, 2010). A World Commission on Environment and Development (1987) apresentou ao mundo o desenvolvimento sustentável, conceituandoo como o desenvolvimento econômico que satisfaz as necessidades da presente geração sem comprometer a capacidade das futuras gerações de satisfazerem suas próprias necessidades.

Barkemeyeret al. (2014) afirmam que a imprecisão do conceito de Desenvolvimento Sustentável vem dando espaço para interpretações muito diferentes, intimamente relacionadas com a dificuldade de medir se uma atividade específica promove ou não o DS. O conceito já recebeu diversas críticas (Hopwood, Mellor e O'Brien, 2005; Fernandes, 2003; Dovers, 1996; Castro, 2004). Um problema apontado sobre o coceito é que "a demasiada utilização do termo 'desenvolvimento sustentável' junto aos contextos organizacionais tem gerado confusões epistemológicas, paradigmáticas e teóricas a seu respeito" (MUNCK et al., 2012, p. 106).

Em relação às organizações, Van Marrewijk e Werre (2003) ressaltam que cada uma delas deve escolher, de acordo com suas próprias ambições, a abordagem com relação à Sustentabilidade Organizacional que mais se adéque aos seus objetivos, estratégia e intenções. Sendo assim, o conceito de Sustentabilidade Organizacional (SO) pode ser considerado um termo ambíguo, já que há um debate considerável no que diz respeito à gama de características das organizações (ANGUS-LEPPAN; BENN; YOUNG, 2010).

Neste sentido, Borim-de-Souza (2010, p. 70) disserta que a Sustentabilidade Organizacional "é uma meta organizacional que permite às organizações contribuírem para o alcance de uma meta social maior: o desenvolvimento sustentável".Passet (1996), por sua via, reforça a ideia relacionada aos três pilares, ao afirmar que a Sustentabilidade Organizacional é composta pelo pilar econômico, pilar ambiental e o pilar social. Segundo o princípio do Triple Bottom Line as organizações sustentáveis devem ter o intuito de alcançar maior sustentabilidade em suas operações, e devem tomar decisões baseadas não somente em 


\section{A INSTITUCIONALIZAÇÃO DO TEMA SUSTENTABILIDADE NO CURSO DE GRADUAÇÃO EM \\ DOI: http://dx.doi.org/10.5007/1983-4535.2018v11n1p298}

retornos financeiros, mas também considerando quesitos como proteção ao meio ambiente e justiça social (ELKINGTON, 1999).

\subsection{ENSINO DA SUSTENTABILIDADE NOS CURSOS DE ADMINISTRAÇÃO}

Existe um consenso, conforme Madeira (2008, p. 19), de que as Instituições de Ensino Superior (IES) "são órgãos privilegiados de propagação do conhecimento através do ensino e da investigação", além de serem as responsáveis pela formação da maioria das pessoas que ocupam cargos relevantes na sociedade. Nessa perspectiva, as IES's, além de serem promotoras, e até mesmo construtoras de conhecimentos pertinentes às temáticas relevantes, inclusive questões ambientais, podendo serem elas, também, geridas a partir de modelos de gestão sustentável (MADEIRA, 2008).

Barbieri e Silva (2011) explicam que as origens da Educação Ambiental (EA), como outros temas, suscitam diferentes periodizações. Atualmente, verifica-se que "a ideologia do Desenvolvimento Sustentável, que ganhou popularidade em meados dos anos 1980, penetrou gradualmente no movimento da educação ambiental e firmou-se como perspectiva dominante.” (BARBIERI; SILVA, 2011, p 14).A Lei $\mathrm{n}^{\mathrm{o}}$ 9.795, que instituiu a Política Nacional de Educação Ambiental, define que:

\footnotetext{
Entendem-se por educação ambiental os processos por meio dos quais o indivíduo e a coletividade constroem valores sociais, conhecimentos, habilidades, atitudes e competências voltadas para a conservação do meio ambiente, bem de uso comum do povo, essencial à sadia qualidade de vida e sua sustentabilidade. (BRASIL, 1999).
}

No que afeta a questão do ensino superior, Jacobi, Raufflet e Arruda (2011, p. 22) observaram em seu estudo "um significativo aumento do número de instituições de ensino superior que apresentam motivação para formar estudantes com conhecimentos e habilidades necessárias para colocar a sustentabilidade no centro de suas futuras atividades de gestão.”Gonçalves-Dias et al. (2009, p. 6) dissertam que “a institucionalização da temática ambiental nas escolas de graduação em Administração tem variado bastante, conforme o contexto e as características culturais das diferentes instituições." Os autores explicam que em algumas escolas a iniciativa se constrói a partir do professor, de forma que esse, através de sua atuação, introduz de maneira gradual e progressiva, abordagens relacionadas com a questão ambiental. Outra forma pode ser a partir da criação de disciplinas específicas, nos cursos de graduação e pós-graduação, por professores envolvidos em programas que de alguma forma tenham afinidade com a questão ambiental. 


\section{A INSTITUCIONALIZAÇÃO DO TEMA SUSTENTABILIDADE NO CURSO DE GRADUAÇÃO EM \\ DOI: http://dx.doi.org/10.5007/1983-4535.2018v11n1p298}

Em pesquisa apresentada por Palma, Oliveira e Viacava (2011) em cursos de graduação em Administração de universidades federais brasileiras, analisaram os currículos dos cursos de Administração ofertados pelas IES, a fim de verificar a existência de temas relacionados ao Desenvolvimento Sustentável. Identificaram que das 40 universidades federais analisadas, apenas 13 (33\%) oferecem cursos relacionados à sustentabilidade, dos quais apenas seis têm cursos que correlacionam ambas as questões: ambiental e social.

Nesse sentido conforme Raufflet (2014, p. 17) "A integração da sustentabilidade com o ensino de administração representa um desafio tanto a nível conceitual quanto a nível institucional para as Escolas de Administração". Nessa perspectiva o autor destaca que os desafios conceituais perpassam a diversidade de interpretações dos termos "desenvolvimento sustentável" como "sustentabilidade"; já no campo institucional, as dificuldades estão na oferta de currículos especializados e técnicos, com foco em abordagens quantitativas, além de que alguns aspectos da cultura da Administração apresentam-se implícitos e, por vezes, explicitamente contrários aos valores da Sustentabilidade (RAUFFLET, 2014).

Jacobi, Raufflet e Arruda (2011), apontam que a promoção da sustentabilidade na educação superior tem enfrentado, principalmente, três dificuldades significativas, a saber: o primeiro é que a maioria das instituições de ensino superior tem dado um enfoque fragmentado para a sustentabilidade, com foco em iniciativas de "esverdeamento" do campus ou de adicionar conteúdo a uma parte específica do currículo. O segundo desafio perpassa a promoção da interdisciplinaridade, como uma condição para a educação da sustentabilidade, a qual tem encontrado muita resistência nas instituições, tendo em vista tanto aspectos administrativos institucionais, como pela relutância dos docentes se engajarem com a interdisciplinaridade e com abordagens mais práticas relacionadas ao tema. E um terceiro desafio apontado pelos autores é a necessidade de uma mudança profunda e duradoura no processo organizacional nas instituições, ou seja, que o ensino superior deve abordar a sustentabilidade de forma mais sistêmica, onde seja possível a Instituição acompanhar e absolver as mudanças em andamento nas organizações e sociedade em geral, e convertendo essas em estratégias de aprendizagem (JACOBI; RAUFFLET; ARRUDA, 2011). 


\section{PROCEDIMENTOS METODOLÓGICOS}

No que se refere à classificação geral essa pesquisa caracteriza-se como qualitativa, com fins descritivos e estudo de caso. A partir da pesquisa qualitativa, buscou-se a profundidade do fenômeno estudado, ou seja, as suas especificidades e contextualizações, assim como a interpretação dos participantes da pesquisa. Godoi e Balsani (2006) defendem que a pesquisa qualitativa busca aprofundar o conhecimento sobre uma determinada realidade, nesse caso, busca-se analisar como se deu o processo de institucionalização do tema sustentabilidade no curso de graduação em Administração.Quanto aos fins, esse estudo tem características de descritivo, uma vez que, conforme Godoy (2006), quando os dados coletados são apresentados por meio de transcrições de entrevista e anotações de campo tratase de uma pesquisa descritiva.

A coleta de dados dessa pesquisa deu-se por meio da análise documental e entrevistas semi-estruturadas. No que se refere à análise documental, adaptou-se critérios utilizados no trabalho de Zuin (2011). Foram verificadas as diretrizes e bases da educação nacional, Diretrizes Curriculares Nacionais dos Cursos de Graduação em Administração e demais pareceres do Conselho Nacional de Educação, que se relacionam ao curso de graduação em Administração, e da Política Nacional de Educação Ambiental (PNEA). Assim como os documentos Institucionais: Plano de Desenvolvimento Institucional; Perfil do profissional do aluno; Perfil profissional e habilidades a serem desenvolvidas no curso em Administração; Projeto pedagógico e estrutura curricular do Curso de Administração.

As entrevistas foram realizadas. Utilizou-se entrevista focada com os principais atores vinculados à concepção do Projeto Pedagógico em vigência na Universidade estudada, na qual a pessoa é entrevistada em um curto espaço de tempo (uma hora, por exemplo), podendo assumir um caráter conversacional, mas seguindo o conjunto de questões determinado no protocolo do estudo de caso. (YIN, 2010).

Esse estudo foi realizado na Universidade Estadual de Londrina - Londrina/PR, considerando os critérios proximidade e conveniência. No que se refere à definição operacional das categorias desse trabalho,considerou-se a teoria de Tolbert e Zucker (1999) e dentro, de cada categoria, utilizou-se de subcategorias de análise conforme Alves (2012). Nesse estudo, a análise de conteúdo (BARDIN, 2006) foi utilizada como técnica de análise de dados. 


\section{APRESENTAÇÃO E ANÁLISE DOS RESULTADOS}

O curso de Administração da Universidade Estadual de Londrina (UEL) foi criado pelo parecer do Conselho Estadual de Educação (CEE) n. ${ }^{\circ}$ 91, de 13 de setembro de 1968, e implantado em 01 de março de 1969. O reconhecimento foi através do Decreto Federal $\mathrm{n}^{\circ}$. 74.018, de 7 de maio de 1974. Existindo há 45 anos, o curso de Administração é ofertado tanto no turno matutino como no noturno. Conforme o Manual do Aluno do curso de Administração (UNIVERSIDADE ESTADUAL DE LONDRINA, 2014b, p. 5), o curso visa:

[...] à formação de administradores aptos a atuar nas organizações em geral, com forte base em valores como responsabilidade social, justiça e ética profissional e com formação humanística e técnica que propicie visão global para compreender o meio social, político, econômico e cultural onde está inserido e a tomar decisões em um mundo diversificado e interdependente (grifo nosso).

Conforme o Conselho Nacional de Educação (CNE) e a Câmara de Educação Superior (CES) os cursos de graduação devem atender a alguns princípios, que asseguram que as instituições de ensino superior tenham liberdade na composição da carga horária, a ser cumprida para a integralização dos currículos, assim como na especificação das unidades de estudos a serem ministradas. Conforme o PPC (UNIVERSIDADE ESTADUAL DE LONDRINA, 2005a, p. 8), o curso de Administração UEL visava "propiciar, através dos conjuntos de atividades didático-pedagógicas, o desenvolvimento das diversas competências e habilidades".

O PPC do curso já foi construído tendo a sustentabilidade como uma questão pertinente. Silva, Campanário e Souza (2013, p. 170) explicam que a Política Nacional de Educação Ambiental (PNEA) estabelece "a inclusão da Educação Ambiental em todos os níveis do ensino de modo transversal e contínuo, vedando sua utilização como disciplina específica." A análise das ementas, do conjunto de disciplinas elencadas no quadro 19, mostrou a existência, na matriz curricular, de três disciplinas com conteúdos aderentes à sustentabilidade no curso de Administração. O quadro 1 apresenta matérias e as ementas com conteúdos relacionados à sustentabilidade. 
Quadro 1 Disciplinas e ementas com conteúdo relacionadas à sustentabilidade

\begin{tabular}{|c|c|c|}
\hline Universidade & Disciplina & Ementa \\
\hline $\begin{array}{l}\text { Universidade } \\
\text { Estadual de } \\
\text { Londrina (UEL) } \\
\text { Campus } \\
\text { Londrina/PR }\end{array}$ & $\begin{array}{l}\text { Fundamentos de } \\
\text { Administração }\end{array}$ & $\begin{array}{l}\text { Origens e a evolução da Administração. Abordagem } \\
\text { socioambiental da Administração. Administração e } \\
\text { sociedade: globalização, competitividade e tecnologia. } \\
\text { Conceito e tipologia das organizações. A ciência da } \\
\text { Administração. Estudo do processo administrativo: } \\
\text { planejamento, organização, direção e controle. O } \\
\text { processo gerencial e o profissional de Administração. } \\
\text { Perfil e espaços de atuação do administrador }\end{array}$ \\
\hline & $\begin{array}{l}\text { Administração } \\
\text { Socioambiental }\end{array}$ & $\begin{array}{l}\text { A problemática ambiental na contemporaneidade; Ações } \\
\text { de sustentabilidade sistêmica; Histórico e conceituação } \\
\text { de gestão ambiental; Gestão ambiental empresarial e } \\
\text { Sistema de gestão ambiental; Auditorias ambientais. }\end{array}$ \\
\hline & $\begin{array}{l}\text { Ética Empresarial e } \\
\text { Responsabilidade } \\
\text { Social Nos Negócios }\end{array}$ & $\begin{array}{l}\text { Histórico e conceituação e visão geral da Filosofia e da } \\
\text { Ética. Código de Ética e Código de Ética do Profissional } \\
\text { em Administração. A ética na gestão empresarial. } \\
\text { Códigos de conduta e procedimento e seus resultados. } \\
\text { Responsabilidade social corporativa. A responsabilidade } \\
\text { social no contexto brasileiro }\end{array}$ \\
\hline
\end{tabular}

Fonte: Adaptado Projeto Pedagógico do Curso de Administração (UNIVERSIDADE ESTADUAL DE LONDRINA, 2009).

Observa-se nas disciplinas e ementas (quadro 1) temas relativos à sustentabilidade no curso de Administração, conforme a classificação de Barbieri e Silva (2010, 2011), Silva (2013), Souza et al. (2011). Duas disciplinas do curso, Fundamentos de Administração e a Administração Socioambiental, são disciplinas que fazem parte dos conteúdos de formação profissional do curso de Administração e a Ética Empresarial e Responsabilidade Social nos Negócios faz parte dos conteúdos de formação básica (Quadro 1).

Nessa perspectiva, conforme Gonçalves-Dias et al. (2009, p. 6) “a institucionalização da temática ambiental nas escolas de graduação em Administração tem variado, conforme o contexto e as características culturais das diferentes instituições." Na UEL, a análise dos documentos indicou a existência do processo de institucionalização da temática sustentabilidade no curso de Administração. Para os autores (BARLEY; TOLBERT, 1997), as estruturas ou instituições são formadas por conjuntos de normas, ações e recursos que repetidamente aplicados levam à reprodução e produção das práticas sociais.

A partir da análise dos Projetos Pedagógicos do curso, evidenciou-se a presença do tema como tema transversal, na organização modular do curso, especificamente no módulo MADA (Módulo de Análise da Dinâmica Ambiental). Isto denota uma perspectiva de 


\section{A INSTITUCIONALIZAÇÃO DO TEMA SUSTENTABILIDADE NO CURSO DE GRADUAÇÃO EM

continuidade da estrutura, assim como a manutenção das regras e rotinas (BARLEY; TOLBERT, 1997; BURNS; SCAPENS 2000; MACHADO; PRIMO, 2014). Holm (1995), por sua via, advoga que no primeiro estágio do processo de institucionalização, as estruturas institucionais abarcam atividades guiadas por uma ordem institucional estabelecida, nesse nível as estruturas são conservadoras contribuindo para a perpetuação de regras de conduta assim como para assegurar que essas sejam cumpridas pelos atores sociais.

A institucionalização é, na perspectiva de Tolbert e Zucker (1999), um conjunto de processos sequenciais - habitualização, objetificação e sedimentação - que indica variabilidade nos níveis de institucionalização. Os estágios da institucionalização propostos pelos autores correspondem ao estado em que os processos se encontram e são: estágio préinstitucional (habitualização); estágio semi-institucional (objetificação); e estágio de total institucionalização (sedimentação). Portanto, Tolbert e Zucker (1999) consideram que o grau de institucionalização é um encadeamento linear de eventos ordenados temporalmente, assim não podendo existir concomitantemente no mundo real.

No que se refere à primeira subcategoria escolhida para análise do processo de habitualização, a inovação, os respondentes foram questionados sobre se a inserção da Sustentabilidade no curso de Administração poderia ser considerada uma inovação na universidade. Sobre esse aspecto a Coordenadora do Colegiado do Curso (CC2) em exercício no curso de Administração da UEL afirmou que:

\footnotetext{
Bom, na verdade o que aconteceu né, com relação a esse currículo [...] ele surgiu de um trabalho, de uma dissertação de um professor do departamento. E, na época, como ele estava estudando assim as matrizes curriculares de outro viés, então o que ele fez? Ele foi tentando buscar justamente essas áreas ou disciplinas que eram consideradas inovadoras, como algo mais contemporâneo.
}

Esse fato, também, foi verificado durante a entrevista realizada com o Professor (PC2) titular de disciplinas relacionadas à sustentabilidade, incorporado ao corpo docente do curso pós-implantação do PPC em vigência.Selznick (1971) ressalta que a institucionalização acontece na organização com o passar do tempo, e reflete sua história particular, ou seja, os colaboradores que nela atuam os interesses dos grupos que a criaram e a maneira como a gestão se adaptou às mudanças do ambiente. Meyer e Rowan (1977) explicam que organização nenhuma poderá continuar a viver ou mesmo ter sucesso se não acatar e evidenciar perante o meio organizacional em que estão inseridas, as práticas, estruturas e sistemas que sejam aceitas como legítimos. 


\section{A INSTITUCIONALIZAÇÃO DO TEMA SUSTENTABILIDADE NO CURSO DE GRADUAÇÃO EM \\ DOI: http://dx.doi.org/10.5007/1983-4535.2018v11n1p298}

No caso do Curso de Administração da UEL, no que se refere às Políticas e Procedimentos, a análise dos conteúdos das entrevistas apontou que o PCC do Curso de Administração da UEL materializou as políticas do curso e foi verificada a presença da sustentabilidade. Em suma, pode-se se verificar que a sustentabilidade encontra-se em fase de pre-institucionalização (habitualização). Conforme Tolbert e Zucker (1999), ações tornadas habituais referem-se a comportamentos desenvolvidos de forma empírica e adotados por um ou mais indivíduos a fim de resolver problemas recorrentes.

$\mathrm{Na}$ fase da objetificação é onde está o movimento em direção a um status mais permanente e disseminado do processo de Institucionalização. Conforme Tolbert e Zuckeressa fase é classificada como estágio semi-institucional e envolve o desenvolvimento de certo grau de consenso social entre os decisores organizacionais a respeito do valor da estrutura e a crescente adoção pela organização com base nesse consenso.

Ao analisar os conteúdos das entrevistas, identificou-se que os respondentes formam recorrentes ao afirmar que a proposta transdisciplinar dos módulos não foi implantado na sua totalidade e esbarra na resistência e "ainda não teve o compromisso de colocá-la em prática conforme ela merece" (PC2). Um elemento importante que se destaca na fase de Objetificação são os champions. Conforme Quinello (2007), esses são os "protetores institucionais" (agentes) com interesse material na definição das práticas gerenciais e no auxílio da manutenção do status quo da organização. Os conteúdos das entrevistas analisados apontam, para a presença de um grupo que advoga pela sustentabilidade. Conforme Quinello (2007) e Santana (2010), na fase da Objetificação, os líderes, ou seja, os defensores das mudanças exercem um papel importante, realizando a tarefa de teorização com o objetivo de atribuir legitimidade. No entanto, a análise da segunda fase do processo de institucionalização demonstrou uma objetificação baixa, uma vez que se verificou a existência de resistência ao tema, que a matriz curricular ainda não foi implantada na sua totalidade, muito tendo em vista a resistência dos professores do curso, não havendo, assim, um consenso no que se aplica ao valor da estrutura.

Concluída a análise do processo de objetificação, parte-se agora para a última fase do processo de institucionalização. Terceira e fase final do processo de institucionalização é a sedimentação. Conforme Tolbert e Zucker (1999) essa fase do processo de institucionalização se apoia na continuidade histórica da estrutura, especialmente em sua sobrevivência pelas várias gerações de membros da organização. A análise dos conteúdos das entrevistas mostrou 


\section{A INSTITUCIONALIZAÇÃO DO TEMA SUSTENTABILIDADE NO CURSO DE GRADUAÇÃO EM \\ DOI: http://dx.doi.org/10.5007/1983-4535.2018v11n1p298}

que os respondentes não vincularam resultados positivos relevantes no que se refere à presença da sustentabilidade na formação dos alunos do curso de Administração. Na fase de sedimentação é importante que as práticas objetivadas e compartilhadas possam ser transmitidas em uma linguagem objetiva, expondo as experiências dos agentes e colaborando para o enriquecimento do estoque de conhecimento já adquirido (QUINELLO, 2007; SANTANA 2010). Nesse sentido, a institucionalização total da estrutura está sujeita ao efeito da baixa resistência por parte de grupos de oposição, da promoção e de um apoio cultural e contínuo por grupos defensores e, principalmente, da correlação positiva com resultados desejados.

A análise da fase Sedimentação demonstrou que, embora tenha ficado evidenciada a importância do tema (conforme conteúdos das entrevistas), e a existência de um grupo de defensores da estrutura, os resultados mostraram que não houve a vinculação de resultados positivos relevantes no que se refere à presença da sustentabilidade na formação dos alunos, assim como a existência de resistência, dos grupos de oposição, denotam que o processo de institucionalização do tema sustentabilidade no curso de Administração da UEL ainda não encontra na fase de sedimentação. Com relação ao tema Sustentabilidade ainda apresenta-se como periférico. A análise dos documentos institucionais (Regimento Geral e Plano de Desenvolvimento Institucional PDI) reforça essa perspectiva, uma vez que não foi identificada a sustentabilidade como elemento sequer mencionado nos textos. Em termos de Universidade (UEL) não se tem a sustentabilidade como incorporada nas suas estruturas organizacionais.

O conteúdo das entrevistas identificou que o tema sustentabilidade está legitimado no pilar regulativo, mas não está na visão do pilar normativo.Com relação ao isomorfismo que segundo Rossetto e Rossetto (2005), pressupõe que as organizações respondem de maneira similar a outras organizações que estão de alguma forma ajustadas ao ambiente. DiMaggio e Powell (1983) explicam que três são os mecanismos por meio dos quais acontecem as mudanças isomórficas: isomorfismo coercivo (provem da política e do problema da legitimidade); isomorfismo mimético (resulta de resposta padrão às incertezas); isomorfismo normativo (associado a profissionalização).

Nesse sentido, análise do conteúdo das entrevistas mostrou que a presença do isomorfismo normativo, materializado na inserção da temática sobre sustentabilidade, que foi inserido no projeto pedagógico do curso, deu-se pela atuação de um grupo de professores que 


\section{A INSTITUCIONALIZAÇÃO DO TEMA SUSTENTABILIDADE NO CURSO DE GRADUAÇÃO EM \\ DOI: http://dx.doi.org/10.5007/1983-4535.2018v11n1p298}

atuaram no sentido de ser a sustentabilidade um tema transversal presente no curso de Administração da UEL. Com relação ao isomorfismo coercitivo Machado-Da-Silva et al. (2003) explica que o isomorfismo coercitivo resulta de pressões formais, assim como depressões informais exercidas sobre as organizações. O Coordenador do Colegiado (CC1) informou que a motivação para a inserção da temática sustentabilidade veio "muito mais uma exigência social do que uma exigência legal" e foi motivada pela busca de uma formação mais ampla para o administrador. Pode-se verificar que o isomorfismo coercitivo se destacou pela pressão social para a formação ampliada do administrador, e que a pressão coercitiva oriunda de instituições legais do Ministério da Educação (MEC), tiveram menos impacto. O que é interessante, uma vez que as exigências legais e normativas do MEC, assim como o conhecimento relativo à Política Nacional de Educação Ambiental (PNEA), que deveriam criar um ambiente legal que obrigasse as organizações a se moldarem (DIMAGGIO; POWELL, 1983; VERNAD; HANAFI, 2008), não se destacou como uma pressão isomórfica coercitiva.

\section{CONSIDERAÇÕES FINAIS}

Empregando como base teórica o trabalho de Tolbert e Zucker (1999), este estudo teve como objetivo geral compreender como se deu o processo de institucionalização do tema sustentabilidade no curso de graduação em Administração da Universidade Estadual de Londrina.

Nesse sentido, as análises mostraram que a opção pelo tema sustentabilidade deu-se de maneira contextual, e não emergiu de uma obrigação legal. Com relação ao processo de institucionalização, demonstrou uma objetificação baixa, verificada nas seguintes constatações: existência de resistência ao tema sustentabilidade, verificação de que a matriz curricular ainda não foi implantada na sua totalidade; não há um consenso no que se aplica ao valor da estrutura. A análise da fase Sedimentação demonstrou que o processo de institucionalização do tema sustentabilidade no curso de Administração da UEL ainda não se encontra na fase de sedimentação, pois não houve a vinculação de resultados positivos no que é pertinente à inserção da sustentabilidade na formação dos alunos, e tem-se a resistência dos grupos de oposição.

Nesse sentido, a partir desse estudo é possível apontar para as seguintes perspectivas: a temática sustentabilidade está pré-institucionalizada no curso de Administração; a opção pela 
temática sustentabilidade no curso de administração da UEL foi apontada como oriunda de exigências sociais, motivada pela busca de uma formação mais ampla para o administrador, que está materializada na proposta da uma matriz curricular que contempla o tema de forma transversal.Vislumbra-se, no entanto, que o estudo desse tema não acaba com esse trabalho, mas esse é o ponto inicial para o desenvolvimento de novas pesquisas. Sugere-se o desenvolvimento de pesquisas que busquem estudar o processo de institucionalização do tema sustentabilidade em outras Instituições de Ensino, tanto públicas como particulares; que procurem estudar a inserção da sustentabilidade em outros níveis acadêmicos, além da graduação, como na pós-graduação (lato sensu) como no mestrado e doutorado (pósgraduação stricto sensu); além de se estender o estudo do tema sustentabilidade na perspectiva da teoria institucional a outros cursos de graduação, tais como Direito, Contabilidade, Engenharia de Produção.

\section{REFERÊNCIAS}

ALVES, R. R. A institucionalização dos cursos de administração pública a distância das universidades públicas: os casos UFLAE UFU. 2012. 198 f. Dissertação (Mestrado em Administração) - Universidade Federal de Lavras, Lavras, 2012.

ANGUS-LEPPAN, T.; BENN, S.; YOUNG, L. A sensemaking approach to tradeoffsandsynergiesbetweenhumanandecologicalelementsofcorporatesustainability.

Business StrategyandtheEnvironment, Sydney, v. 19, n. 4, p. 217-229, 2010. Disponível em: $<$ http://onlinelibrary.wiley.com/doi/10.1002/bse.674/pdf >. Acesso em: 12 jan. 2015.

Barb_. Educação ambiental na formação do administrador. São Paulo: Cegage Learning, 2011. 246 p.

BARBIERI, I. C.; SILVA, D. Educação ambiental e gestão ambiental na formação do administrador: uma visão do quadro regulatório. In: MORETTI, S. L. A. (Ed.). Ensino e pesquisa em administração: proposta para capacitação docente. São Paulo: CAPES, 2010. p. 151-172.

BARDIN, L. Análise de conteúdo. Lisboa: Edições 70, 2006. 223 p.

BARKEMEYER, R. et al. Whathappenedtothe 'development' in sustainabledevelopment? Business guidelines two decades after brundt land. Sustainable Developlment, Sydney, v. 22, n. 1, p. 15-32, Jan./Feb. 2014.

BARLEY, S. R.; TOLBERT, P. S. Institutionalizationandstructuration: studyingthe links betweenactionandinstitution. OrganizationStudies, Berlin, v. 18, n. 1, p. 93-117, Jan. 1997.

BORIM-DE-SOUZA, R. O alinhamento entre sustentabilidade e competências em contexto organizacional. 2010. 199 f. Dissertação (Mestrado em Administração) - Programa 
de Pós-Graduação em Administração, Universidade Estadual de Maringá, Universidade Estadual de Londrina, Londrina, 2010.

BRASIL. Resolução $\mathrm{n}^{\mathrm{o}}$ 4, de 13 de julho de 2005. Institui as Diretrizes Curriculares Nacionais do Curso de Graduação em Administração, bacharelado, e dá outras providências. Disponível em: <http://portal.mec.gov.br/cne/arquivos/pdf/rces004_05.pdf $>$. Acesso em: 10 out. 2014.

BURNS, J.; SCAPENS, R. W. Conceptualizing management accountingchange: aninstitutional framework. Management AccountingResearch, London, v. 11, n. 1, p. 3-25, 2000 .

CARVALHO, C. A. P. VIEIRA, M. M. F.; LOPES, F. D. Contribuições da perspectiva institucional para análise das organizações. In: ENCONTRO DA ANPAD, 23., 1999, Foz do Iguaçu. Anais... Foz do Iguaçu, 1999.

CARVAlHO, C. A.; VIEIRA, M. M. F.; SILVA, S. M. G. A trajetória conservadora da teoria institucional. Revista de Administração Pública, Rio de Janeiro, v. 10, p. 469-496, dez. 2012.

CASTRO, C. J. Sustainabledevelopment: mainstreamandcritical perspectives. Organization\&Environment, Surrey, v. 17, n. 2, p. 195-225, Jun. 2004.

CRUBELLATE, J. M. Três contribuições conceituais neo-funcionalistas à teoria institucional em organizações. Revista de Administração Contemporânea, Curitiba, v. 11, n. $1,2007$.

DIMAGGIO, P. J.; POWELL, W. W. The ironcagere visited: institutionaliso morphism and collectiverationality in organizational fields. American SociologicalReview, AlisoViejo, v. 48, p. 147-160, Apr. 1983.

DOVERS, S. R. Sustentability: demands on policy. Journal of Public Policy, Cambridge, v. 16, n. 3, p. 303-318, Sep. 1996.

ELKINGTON, J. Cannibals with forks: the triple bottomline of 21st century business. Oxford: Capstone Publishing Limited, 1999.

FERNANDES, M. Desenvolvimento sustentável: antinomias de um conceito. In:

FERNANDES, M.; GUERRA, L. (Org.). Contra discurso do desenvolvimento sustentável. Belém: Associação de Universidade da Amazônia, 2003. p. 131-169.

FREITAS, C. A. S.; GUIMARÃES, T. A. Isomorfismo, institucionalização e legitimidade: a atividade de auditoria operacional no Tribunal de Contas da União. In: ENCONTRO DA ANPAD, 29., 2005, Brasília. Anais... Brasília, 2005.

GODOI, C. K.; BALSINI, C. P. V. A pesquisa qualitativa nos estudos organizacionais brasileiros: uma análise bibliométrica. In: SILVA, A. B.; GODOI, C. K.; MELLO, R. 
(Org.). Pesquisa qualitativa em estudos organizacionais: paradigmas, estratégias e métodos. São Paulo: Saraiva, 2006. p. 89-114.

GODOY, A. S. Estudo de caso qualitativo. In: SILVA, A. B.; GODOI, C. K.; MELLO, R. (Org.). Pesquisa qualitativa em estudos organizacionais: paradigmas, estratégias e métodos. São Paulo: Saraiva, 2006. p. 20-29.

GONCALVES-DIAS, S. L. F. et al. Consciência ambiental: um estudo exploratório sobre suas implicações para o ensino de administração. RAE Eletrônica, São Paulo, v. 8, n. 1, 2009. Disponível em: <http://www.scielo.br/pdf/raeel/v8n1/a04v8n1.pdf > Acesso em: 16 jan. 2014.

HOLM, P. The dynamics of Institutionalization: transformation processes in Norwegian fisheries. Administrative Science Quarterly, Ithaca, v. 40, n. 3, p. 398-422, Sep. 1995.

HOPWOOD, B.; MELLOR, M.; O'BRIEN G. Sustainable development: mapping different approaches. Sustainable Development, Sydney, v. 13, n. 1, p. 38-52, 2005. Disponível em: $<$ http://onlinelibrary.wiley.com/doi/10.1002/sd.244/abstract>. Acesso em: 10 ago. 2014.

JACOBI, P. R.; RAUFFLET, E.; ARRUDA, M. P. Educação para a sustentabilidade nos cursos de administração: reflexão sobre paradigmas e práticas. Revista de Administração Mackenzie, São Paulo, v. 12, n. 3, p. 21-50, jun. 2011.

LAWRENCE, T. B.; WINN, M. I.; JENNINGS, P. D. The temporal dynamics ofinstitucionalization. Academy of Management Review, Mississipi, v. 26, n. 4, p. 624-644, Oct. 2001.

MACHADO, F. O.; PRIMO, M. A. M. Teoria das restrições tratada sob a égide das rotinas e da estruturação social. In: SIMPÓSIO DE ADMINISTRAÇÃO DA PRODUÇÃO, LOGÍSTICA E OPERAÇÕES INTERNACIONAIS, 17., 2014, São Paulo. Anais... São Paulo, 2014.

MACHADO-DA-SILVA, C. L. et al. Institucionalização da mudança na sociedade brasileira: o papel do formalismo. In: VIEIRA, M. M. F.; CARVALHO, C. A. (Org.). Organizações, instituições e poder no Brasil. Rio de Janeiro: FGV, 2003. p. 179-202.

MACHADO-DA-SILVA, C. L.; FONSECA, V. S. Competitividade organizacional: uma tentativa de reconstrução analítica. Revista de Administração Contemporânea, Curitiba, v. 14, p. 33-49, set. 2010.

MADEIRA, A. C. F. D. Indicadores de sustentabilidade para instituições de ensino superior. 2008. 185 f. Dissertação (Mestrado em Engenharia do Ambiente) - Faculdade de Engenharia, Universidade do Porto, Porto, 2008.

MEYER, J. W. The effectsofeducation as aninstitution. American JournalofSociology, Chicago, v. 83, n. 2, p. 53-77, 1977. 
MUNCK, L. et al. Estudos organizacionais e desenvolvimento sustentável: em busca de uma coerência teórica e conceitual. Interações, Campo Grande, v. 13, n. 1, p. 105-120, jan./jun. 2012.

PALMA, L. C.; OLIVEIRA, L. M.; VIACAVA, K. R. Sustainability in brazilian federal universities. International Journal of Sustainability in Higher Education, Ithaca, v. 12, n. 3, p. 250-258, 2011.

PASSET, R.L’economique et levivant. Paris: Econômica, 1996.

QUINELLO, R. A teoria institucional aplicada à administração: entenda como o mundo invisível impacta na gestão dos negócios. São Paulo: Novatec Editora, 2007.

RAUFFLET, E. Formas de integração da sustentabilidade ao ensino de administração. In: BRUNSTTEIN, J.; GODOY, A. S.; SILVA, H. C. (Org.). Educação para sustentabilidade nas escolas de administração. São Carlos: RiMa Editora, 2014. p. 15-26.

ROSSETTO, C. R.; ROSSETTO, A. M. A teoria institucional e dependências de recursos na adaptação organizacional: uma visão complementar. RAE-Eletrônica, São Paulo, v. 4, n. 1, p. 1-22, jan./jul. 2005.

SANTANA, G. A. S. Institucionalização de instrumentos gerenciais: o caso de uma organização do setor elétrico. 2010. 120 f. Dissertação (Mestrado em Ciências Contábeis) Universidade Federal de Minas Gerais, Belo Horizonte, 2010.

SCOTT, W. R.Institutions and organizations. Thousand Oaks: Sage, 1995.

SELZNICK, P. A liderança na administração: uma interpretação sociológica. Rio de Janeiro: FGV, 1971.

Institutionalism "old" and "new". Administrative Science Quarterly, Ithaca, v. 41, n. 2, p. $270-277,1996$.

SILVA, H. H. M. O isomorfismo na educação ambiental como tema transversal em cursos de graduação em administração. 2013. 134 f. Dissertação (Mestrado em Administração) - UNINOVE, São Paulo, 2013.

SILVA, H. H. M.; CAMPANÁRIO, M. A.; SOUZA, M. T. S. O isomorfismo na educação ambiental como tema transversal em programas de graduação em administração. Revista de Ciências da Administração, Florianópolis, v. 15, n. 37, p. 170-186, dez. 2013.

SOUZA, M. T. S. et al. Perfil e evolução da pesquisa em sustentabilidade ambiental: uma análise bibliométrica. In: ENCONTRO DA ASSOCIAÇÃO NACIONAL DE PESQUISA EM ADMINISTRAÇÃO, 35., 2011, Rio de Janeiro. Anais... Rio de Janeiro, 2011.

TOLBERT, P. S.; ZUCKER, L. G. A institucionalização da teoria institucional. In: CLEGG, S. R.; HARDY, C.; NORD, W. R. (Org.). Handbook de estudos organizacionais. São Paulo: Atlas, 1999. p. 194-217. 
UNIVERSIDADE ESTADUAL DE LONDRINA - UEL. Catálogo dos cursos de graduação: 2014. Disponível em: <http://www.uel.br/prograd/catalogocursos/catalogo_2013/documentos/apresentacao.pdf>. Acesso em: 1 nov. 2014a. \begin{tabular}{c} 
Manual do aluno: \\
\hline$<\mathrm{http}: / / \mathrm{w} w w$. cursol.br/cesa/adm/pages/manual-do-academico.php $>$. Acesso em: 1 nov. $2014 \mathrm{~b}$.
\end{tabular}

. Resolução CEPE no 351/2005a. Reformula o Projeto Político-Pedagógico do Curso de Administração, a ser implantado para os ingressantes no curso no ano letivo de 2006. Disponível em: $<$ http://www.uel.br/prograd/pp/documentos/adm_2006.pdf $>$. Acesso em: 9 dez. 2014.

VAN MARREWIJK, M. Concepts and definitions of csrand corporate sustainability: between agency and communion. Journal of Business Ethics, Dordrecht, v. 44, n. 2-3, p. $95-$ $105,2003$.

VAN MARREWIJK, M.; WERRE, M. Multiple levels of corporate sustainability. Journal of Business Ethics, Dordrecht, v. 44, n. 2-3, May 2003.

VERNAD, B.; HANAFI, M. Organizationalisomorphism and corruption in financial institutions: empirical research in emerging countries. Journalof Business Ethics, Dordrecht, n. 81, p. 481-498, 2008.

VIEIRA, S. F. A. O parque tecnológico de Londrina: uma análise à luz da teoria neoinstitucional. 2005. 194 f. Dissertação (Mestrado em Administração) - Programa de PósGraduação em Administração, Universidade Estadual de Londrina, Londrina, 2005.

WORLD COMMISSION ON ENVIRONMENT AND DEVELOPMENT - WCED. Our common future. Oxford: Oxford University Press, 1987.

YIN, R. K. Estudo de caso: planejamento e métodos. 4. ed. Porto Alegre: Bookman, 2010.

ZUIN, V . A inserção da dimensão ambiental na formação de professores de química. Campinas: Átomo, 2011. 